\title{
Microscopic Identification of Etiological Agents of Mycotic Keratitis in Corneal Ulcer Patients at Tertiary Care Eye Hospital, Pondicherry
}

\author{
I. Gubert Joseph ${ }^{1}$, Selvaraj Stephen ${ }^{2 *}$ (D), N. Shivananda ${ }^{1}$ and \\ Thiruvenkada Krishnan ${ }^{1}$
}

${ }^{1}$ Aravind Eye Hospital and Post Graduate Institute, Pondicherry, India. ${ }^{2}$ Department of Microbiology, Mahatma Gandhi Medical College \& Research Institute, Sri Balaji Vidyapeeth (Deemed - to - be - University), Pondicherry, India.

\begin{abstract}
Fungal keratitis is one of the causes of severe ocular morbidity and blindness. The prevalence of fungal keratitis has been increased from $7-63 \%$. Culture is mandatory for an Ophthalmologist to guide treatment. The main objective of this study is to identify the etiological agents of Mycotic keratitis in corneal ulcer patients based on the microscopy. A prospective study was conducted with a total of 200 corneal scrapings were collected during the period of January to Setember 2015. Direct smear examination was followed by culture on blood agar and Sabraoud Dextrose agar and incubated at $37^{\circ} \mathrm{C}$ for 48 hours (BA) and $25^{\circ} \mathrm{C}$ for seven days (SDA) $48 \mathrm{hrs}$. The cultures are stored in sterile distilled water. Fungus was isolated from 79 (39.5\%) corneal ulcer patients. Out of which 32 (40.5\%) were positive with $10 \% \mathrm{KOH}$. In the present study, $85 \%$ fungal ulcers were diagnosed in female patients and $15 \%$ in male. Among 79 fungus, Aspergillus species, Fusarium species, Curvularia species and unidentified dematiaceous fungi were isolated from corneal ulcers. The bacterial agents were identified in 10 patients $(5.0 \%)$ by direct gram stain as well as culture. Females are the most prevalent for corneal ulcers. Diagnosis of fungal keratitis patients occurs mostly with Fusarium. It suggests that the most of our corneal ulcer patients are infected with the Fusarium. Another risk factor is contact lens for microbial keratitis at the adult age group in Pondicherry. Majority of the fungal keratitis infections have responded to voriconazole for medical management.
\end{abstract}

Keywords: Fungal keratitis, Aspergillus, Fusarium, Potassium hydroxide, Slide culture technique

*Correspondence: stephens4950@gmail.com; +91-9894383368

(Received: February 10, 2020; accepted: February 29, 2020)

Citation: I. Gubert Joseph, Selvaraj Stephen, N. Shivananda and Thiruvenkada Krishnan, Microscopic identification of an etiological agents on Mycotic Keratitis in Corneal ulcer patients at tertiary care eye hospital, Pondicherry, J. Pure Appl. Microbiol., 2020, 14(1):591-594. https://doi.org/10.22207/JPAM.14.1.61

(C) The Author(s) 2020. Open Access. This article is distributed under the terms of the Creative Commons Attribution 4.0 International License which permits unrestricted use, sharing, distribution, and reproduction in any medium, provided you give appropriate credit to the original author(s) and the source, provide a link to the Creative Commons license, and indicate if changes were made. 


\section{INTRODUCTION}

In developing countries, fungal keratitis is one of the causes of severe ocular morbidity and blindness. It's most likely related to the immunosuppressive conditions which occurred because of previous surgeries, along with the continuous usage of steroid eye drops, and the soft contact lenses ${ }^{1-4}$. In India, the prevalence of fungal keratitis of $7-63 \%$ was recorded ${ }^{4}$ The patient presenting with clinical features of bacterial corneal ulcer will often have rapid onset of pain, conjunctival infection and photophobia and sometimes a vision loss will occurs ${ }^{2-5}$. On examination of ulcers by Slit Lamp it appears as clear defined infiltrates with inflammation and edema $^{5-10}$. Culture by an ophthalmologist is often necessary to guide treatment ${ }^{11-12}$. Laboratory evaluation is necessary to establish the diagnosis and to guide the antibiotic therapy ${ }^{8}$. Epidemiology of fungal corneal ulcers is in relation to age, sex, mode of injury, clinical presentation, etiology and the response to treatment with topical and systemic anti-fungal medications $s^{13}$. The main objective of this study is to identify the etiological agents of Mycotic keratitis in corneal ulcer patients based on the microscopy.

\section{MATERIALS AND METHODS}

A prospective study was conducted at Department of Cornea and Microbiology, Aravind Eye Hospital and Post Graduate Institute, Puducherry. The patients with clinical presentation of corneal ulcers and their demographic details such as sex, age, occupation and place of work were included in this study. A total of 200 corneal scrapings were collected during the period of January to July 2015. This research project was approved by the Institutional Human Ethics Committee (IHEC) IRB201400149. The patient was examined with the help of Slit Lamp microscope and the scrapings were prepared with sterile distilled water. Direct smear examination from corneal ulcers, show fungal elements. Scrapped material was inoculated into Blood agar was incubated at $37^{\circ} \mathrm{C}$ for $48 \mathrm{hrs}$. Sabraoud's Dextrose Agar (SDA) were inoculated and incubated at $25^{\circ} \mathrm{C}$ for one week. The micro organisms were identified and fungal stock cultures were stored in sterile distilled water. Culture showed same fungal growth on many inoculation sites. By performing Slide culture technique, the morphology of the fungi was observed by microscopically using Lactophenol cotton blue mount. Subcultures are made and stocked in sterile distilled water.

\section{RESULTS}

About 200 patients who had clinical presentation of corneal ulcers were included in this study. Infection is more in females than the male from the age of 40-60 years. Fungus was isolated from 79 (39.5\%) corneal ulcer patients. Out of which 32 (40.5\%) were positive with $10 \%$ $\mathrm{KOH}$ by direct smear examination and this was confirmed by Slide culture technique. In the present study, $85 \%$ fungal ulcers were diagnosed in female patients than the male. Among 79 fungus were isolated from the scrapings which includes, Aspergillus species - 29 (36.7\%), Fusarium species -43 (54.4\%) (Fig. - 1), Curvularia species - 3 (3.7\%) (Fig. -2 ) and unidentified dematiaceous fungi -4

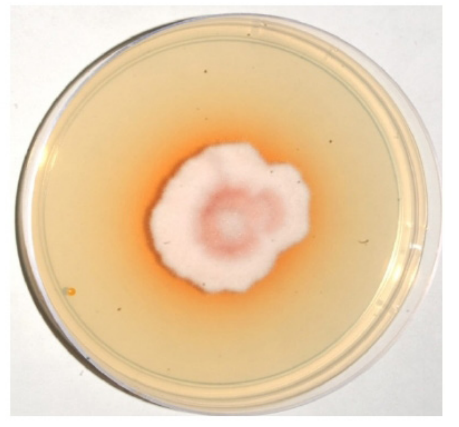

1a. SDA inoculation of Fusarium species

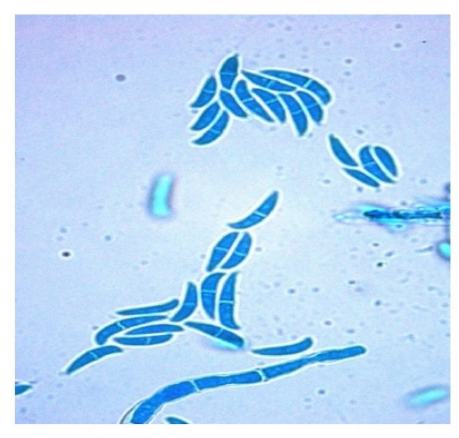

1b. LPCB Microscopic view of Fusarium

Fig. 1. Phenotypic and Microscopic identification of Curvularia species by Lacto-Phenol Cotton blue 

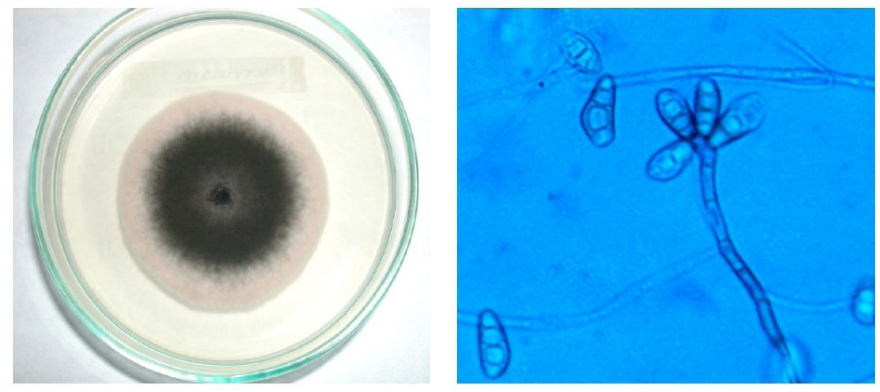

2a. SDA inoculation of Curvularia species

2b. LPCB Microscopic view of Curvularia

Fig. 2. Phenotypic and Microsopic identification of Curvularia species by Lacto-Phenol Cottone blue

(5.0\%). The bacterial agents were identified in 10 patients $(5.0 \%)$ by direct gram stain as well as culture.

\section{DISCUSSION}

Corneal ulcer is more prevalent in males, most predominantly the farmers ${ }^{4,14}$. But in the present study females are the most prevalent for corneal ulcers. The common predisposing factor is Ocular trauma with vegetative matter ${ }^{15}$. In corneal ulcer, the most commonly retrieved organisms are Fusarium species when compared to the other fungal agents ${ }^{2,16}$. In the present study, the isolation of fungi from fungal keratitis patients was mostly Fusarium species followed by Aspergillus and Curvularia species. Recently studies from tertiary care ophthalmic center revealed that Fusarium species had more number of cases in 2011 followed by 2015 and 2016 particularly from North India ${ }^{16}$. In case of dematiaceous fungi they were isolated significantly higher in the year of 2001 and $2003^{16}$. Though in this study, the unidentified dematiaceous fungi were isolated and these isolates have been limited and sent to the regional centers for identification and characterization. Most of the untreated microbial keratitis may result in endophthalmitis and similarly loss of the vision ${ }^{17}$. The highest percentage of fungal isolations was observed in September and low number of cases was observed in June ${ }^{16}$. In the present study, most of the isolations were observed in the month of July to September by comparing with the literature to our findings.

\section{CONCLUSION}

Present study suggests that the most of our corneal ulcer patients are infected with the Fusarium species followed by Aspergillus species. Another risk factor is contact lens for emergence of microbial keratitis at the adult age group in Pondicherry. Majority of the fungal keratitis infections have responded to voriconazole for medical management which recently was found that it was inferior to natamycin in the Mycotic Ulcer Treatment Trail.

\section{ACKNOWLEDGMENTS}

None.

\section{CONFLICT OF INTEREST}

The authors declares that there is no conflict of interest.

\section{FUNDING \\ None.}

\section{AUTHORS' CONTRIBUTIONS}

All authors listed have made a substantial, direct and intellectual contribution to the work, and approved it for publication.

\section{DATA AVAILABILITY}

All datasets generated or analyzed during this study are included in the manuscript and/or the Supplementary Files.

\section{ETHICS STATEMENT}

Not applicable.

\section{REFERENCES}

1. Araki-Sasaki K, Fukumoto AT, Osakabe Y, Kimura $H$, Kuroda S. The clinical characteristics of fungal keratitis in eyes after Descemet's stripping and automated 
endothelial keratoplasty. Clinical Ophthalmology, 2014: 8: 1757-1760. https://doi.org/10.2147/OPTH. S67326

2. Karthikeyan RS, Lea SM, Prajna NV, Dharmalingam K, Geiser DM, Pearlman E, Lalitha P. Expression of Innate and Adaptive Immune Mediators in Human Corneal Tissue Infected With Aspergillus or Fusarium. J Infect Dis., 2011: 204: 942-950. https://doi.org/10.1093/ infdis/jir426

3. Srinivasan $M$, Mascarenhas J, Rajaraman R, Ravindran M, Lalitha P, O'brien KS, Glidden DV, Ray KJ, Oldenburg $C E$, Zegans ME, Whitcher JP, Mcleod SD, Porco TC, Lietman TM, Acharya NR, For The Steroids For Corneal Ulcers Trial Group. The Steroids for Corneal Ulcers Trial (SCUT): Secondary 12-Month Clinical Outcomes of a Randomized Controlled Trial. Am. J. Ophthalmol, 2014; 157(2): 327-333. https://doi.org/10.1016/j. ajo.2013.09.025

4. Khor WB, Aung T, Saw SM, et al. An outbreak of Fusarium keratitis associated with contact lens wear in Singapore. JAMA, 2006; 295: 2867-73.

5. Verma S, Sharma V, Kanga A, Sharma R, Angrup A, Mokta K, Garg A. Current spectrum of oculomycosis in North India: A 5-year retrospective evaluation of clinical and microbiological profile. Indian J Med Microbiol., 2016; 34: 72-75. https://doi.org/10.4103/0255-0857.174104

6. Katara RS, Patel ND, Sinha M. A Clinical Microbiological Study of Corneal Ulcer Patients at Western Gujarat, India. Acta Medica Iranica, 2013; 51: 399-403.

7. Leck AK, Thomas PA, Hagan M, Kaliamurthy J, Ackuaku E, John M, Newman MJ, Codjoe FS, Opintan JA, Kalavathy CM, Essuman V, Jesudasan CA, Johnson GJ. Aetiology of suppurative corneal ulcers in Ghana and south India, and epidemiology of fungal keratitis. Br J Opthalmol., 2002; 86(11): 1211-5. https://doi. org/10.1136/bjo.86.11.1211

8. Jones DB. Diagnosis and management of fungal keratitis. In: Duane CT, ed. Duane's Clinical Ophthalmology. Vol 4. Philadelphia, Pa: Lippincott, 1998; CD-ROM edition

9. Khanna B, Deb M, Panda A, Sethi Harindersingh. Laboratory diagnosis in ulcerative keratitis.
Opthalmic Res., 2005; 37(3): 123-7. https://doi. org/10.1159/000084273

10. Shokohi T, Nowroozpoor-Dailami K, Moaddel-Haghighi T. Fungal keratitis in patients with corneal ulcer in Sari, Northern Iran. Arch Iran Med., 2006; 9: 222-7.

11. Bakshi R, Rajagopal R, Sitalakshmi G, Sudhir RR, Madhavan HN, Bagayalakshmi R. Clinical and Micrbiological Profile of Fungal Keratitis: A 7-Year Study at a Tertiary Hospital in South India. AIOC Proceedings. Cornea Session-III; 2008. p. 207-9.

12. Bharathi MJ, Ramakrishnan R, Meenakshi R, Padmavathy S, Shivakumar C, Srinivasan M. Microbial keratitis in South India: influence of risk factors, climate, and geographical variation. Ophthalmic Epidemiol., 2007; 14: 61-9. https://doi. org/10.1080/09286580601001347

13. Geethakumari PV, Remya R, Girijadevi PS, Reena A. Bacterial Keratitis and Fungal Keratitis in South Kerala: A Comparative Study. Kerala J Ophthalmol, 2011; XXIII:43-46.

14. Saha S, Banerjee D, Khetan A, Sengupta J. Epidemiological profile of fungal keratitis in urban population of West Bengal, India. Oman J Ophthalmol., 2009; 2: 114-8. https://doi.org/10.4103/0974$620 \times .57310$

15. Shi W, Wang T, Xie L, Li S, Gao H, Liu J, Li H. Risk Factors, Clinical Features, and Outcomes of Recurrent Fungal Keratitis after Corneal Transplantation. Ophthalmology, 2010; 117: 890-896. https://doi. org/10.1016/j.ophtha.2009.10.004

16. Satpathya S, Ahmed NH, Nayak N, Tandon R, Sharma N, Agarwal T, Vanathi M, Titiyal JS. Spectrum of mycotic keratitis in north India: Sixteen years study from a tertiary care ophthalmic centre. J Infect Public Heal, 2019; 12(3): 367-371. https://doi.org/10.1016/j. jiph.2018.12.005

17. Byrd LB, Martin N. Corneal Ulcer. [Updated 2019 May 13]. In: StatPearls [Internet]. Treasure Island (FL): StatPearls Publishing; 2020 Jan-. Available from: https://www.ncbi.nlm.nih.gov/books/NBK539689/ 